\title{
Improving communication between the physician and the COPD patient: an evaluation of the utility of the COPD Assessment Test in primary care
}

This article was published in the following Dove Press journal:

Patient Related Outcome Measures

10 November 2014

Number of times this article has been viewed

\section{Shahrzad M Lari \\ Davood Attaran \\ Mohammad Tohidi}

COPD Research Center, School of Medicine, Mashhad University of

Medical Sciences, Mashhad, Iran
Correspondence: Shahrzad M Lari COPD Research Center, School of Medicine, Mashhad University of Medical Sciences, 2/99 Asrar E Gharbi, Kouye Doctora, 91836-3387I, Mashhad, Iran Tel +985I 18452145

Email larish@mums.ac.ir

\begin{abstract}
Chronic obstructive pulmonary disease (COPD) is a leading cause of morbidity and mortality worldwide. It is now considered a systemic inflammatory syndrome and is associated with important comorbidities. In addition to spirometry for evaluating the severity of airflow obstruction, an instrument is required for comprehensive assessment of the disease. The COPD Assessment Test (CAT) is a simple and valid tool for evaluating patient symptoms. The CAT can improve patient-physician communication during routine clinical visits and is useful for assessing functional status and response to treatment. The CAT has a strong correlation with other health status questionnaires, such as the St George's Respiratory Questionnaire. The main advantages of the CAT are its thorough coverage of the important clinical aspects of disease burden and the shorter time involved in completing it. The aim of this paper is to review the role of the CAT, to compare it with other health-related quality of life questionnaires in the assessment and management of COPD patients, and to emphasize the importance of patientphysician communication in the management of patients with the disease.
\end{abstract}

Keywords: chronic obstructive pulmonary disease, assessment test, communication, health status

\section{Introduction}

Chronic obstructive pulmonary disease (COPD) is a preventable and treatable condition characterized by persistent and progressive airflow limitation due to a heightened inflammatory response of the lungs to noxious inhaled gases or particles. ${ }^{1-3}$ COPD is the fourth leading cause of death globally and is a major cause of morbidity. ${ }^{4}$ Worldwide, it is estimated that 64 million people have $\mathrm{COPD}^{5,6}$ and the prevalence may be much higher considering the number of underdiagnosed cases. ${ }^{7}$ COPD usually presents with dyspnea, chronic cough, and chronic sputum production, with a history of smoking and exposure to environmental risk factors. ${ }^{1}$ In addition to clinical symptoms, spirometry is required to make the diagnosis. ${ }^{2}$ A post-bronchodilator forced expiratory volume in one second $\left(\mathrm{FEV}_{1}\right)$ / forced vital capacity $(\mathrm{FVC})<70 \%$ confirms persistent airflow obstruction. ${ }^{1}$ Although the main pathologic process occurs in the lungs, COPD is often accompanied by other serious systemic illnesses, ${ }^{2}$ that have a considerable role in the morbidity and mortality of the disease. ${ }^{1}$ The important comorbidities associated with COPD are cardiovascular disease, psychological problems (depression and anxiety), skeletal muscle dysfunction, diabetes, metabolic syndrome, osteoporosis, and lung cancer. ${ }^{1}$ During assessment and evaluation of the severity of airway disease, special attention should be paid to the possible existence of comorbidities. 
When assessing a patient with COPD, it is important to determine the severity of their symptoms, the severity of airflow obstruction, the frequency of exacerbations, and the presence of disease-related comorbidities. ${ }^{1}$

\section{Assessment of symptoms Patient-physician consultations}

Adequate assessment of the patient with COPD relies on effective patient-physician communication and gathering of reliable information about daily symptoms, severity of dyspnea, exercise limitation, and other COPD symptoms. ${ }^{8}$ An effective consultation is the first step in the management and care of these patients. ${ }^{9-11} \mathrm{~A}$ full assessment of COPD symptoms is the mainstay of patient-physician consultation. Communication whereby physicians are directly involved in and respond to patients' concerns is most effective in COPD management. ${ }^{9}, 12$ The quality of patient-physician communication can influence the patient's adherence with treatment. ${ }^{13}$

Concordance between the physician and patient in terms of perception of the severity of symptoms is important in the clinical management of COPD. ${ }^{14}$ Conversely, lack of a systematic approach to the patient's symptoms during clinical evaluation and insufficient time devoted to the patient can lead to poor concordance ${ }^{14}$ and inappropriate decisions by the physician. ${ }^{14}$ It is strongly recommended that structured communication strategies be used to canvas each patient's beliefs and to implement health behaviors. ${ }^{15}$

In the past, assessment of COPD symptoms was limited to evaluation of dyspnea using standard questionnaires like the modified Medical Research Council (mMRC) instrument, as shown in Table $1 .{ }^{1}$ As mentioned earlier, it is now well accepted that COPD is a systemic disorder, and assessment of all components of the disease is necessary in clinical evaluation. ${ }^{16}$

The 2011 GOLD (Global Initiative for Chronic Obstructive Lung Disease) guidelines emphasize the

Table I Modified Medical Research Council questionnaire

Grade 0 I only get breathless with strenuous exercise

Grade I I get short of breath when hurrying on level ground or walking up a slight hill

Grade 2 On level ground, I walk slower than people of the same age because of breathlessness, or have to stop for breath when walking at my own pace

Grade 3 I stop for breath after walking about 100 yards or after a few minutes on level ground

Grade $4 \mathrm{I}$ am too breathless to leave the house or I am breathless when dressing importance of comprehensive assessment of patient's symptoms and their health status in addition to performing lung function studies. ${ }^{1}$ Health status, functional status, and quality of life are separate concepts and should not be viewed as interchangeable. ${ }^{17}$ Perceptions of health status and functional status are indicators of quality of life.${ }^{17}$ Health-related quality of life (HRQL) is a combination of physical, social, and psychological health. ${ }^{18-20}$ Disease status, covering COPD activity, progression, and prognosis, should also be taken into account when considering these definitions. ${ }^{21}$

COPD-related symptoms like dyspnea, skeletal muscle dysfunction, cough, airflow limitation, frequency of COPD exacerbations, and comorbidities can impair HRQL in COPD patients. ${ }^{22}$ With increasing disease severity, there is a significant deterioration in HRQL. ${ }^{23}$ Frequent exacerbations can also have a deleterious long-term effect on HRQL in COPD. ${ }^{24}$ Reducing the disease burden is one of the main goals of treating COPD. ${ }^{17}$ Instruments for assessment of HRQL can be used to measure the disease burden and the impact of COPD.${ }^{17} \mathrm{HRQL}$ is significantly impaired in all stages of COPD severity. ${ }^{7}$ Due to the multisystem nature of COPD, instruments that reveal the many characteristics of COPD and the effects of disease burden on patients' health status are needed. ${ }^{11}$ Measurement of health status in COPD patients evaluates information complementary to that obtained by spirometry. ${ }^{25}$

\section{COPD Assessment Test}

Given the importance of evaluating HRQL in COPD patients, a simple and valid tool known as the COPD Assessment Test (CAT) was introduced in 2009 by Jones et al. ${ }^{9,25}$ The CAT is a short and reliable test for monitoring HRQL over time and is a valuable tool for measuring outcomes in COPD patients. ${ }^{18,25,26}$

The CAT is completed by patients themselves and consists of eight items related to their symptoms and activity levels. ${ }^{10}$ Items evaluated in the CAT include cough, phlegm, chest tightness, breathlessness during activities, limitations on activity at home, confidence in leaving home, sleep, and energy levels. ${ }^{18,26}$ Each item has a score range of $0-5$, with a maximum score of 40 (Table 2). ${ }^{18,26}$ CAT scores are correlated with important clinical parameters and can be used to evaluate the patient during periods of stability and during exacerbations. ${ }^{27,28} \mathrm{CAT}$ scores have been shown to decrease following recovery from an exacerbation and after pulmonary rehabilitation. ${ }^{25,29} \mathrm{CAT}$ also improves patient-physician communication, ${ }^{9}$ and can assess the impact of COPD on a patient's health status. ${ }^{28}$ It should be noted that the CAT 
Table 2 Classification of airway obstruction

\begin{tabular}{llll}
\hline $\begin{array}{l}\text { GOLD } \\
\text { classification }\end{array}$ & Severity & FEV $/$ IFVC & FEV \\
\hline I & Mild & $<0.70$ & $\begin{array}{l}\mathrm{FEV}_{1} \geq 80 \% \\
\text { predicted }\end{array}$ \\
2 & Moderate & $<0.70$ & $\begin{array}{l}50 \% \leq \mathrm{FEV},<80 \% \\
\text { predicted }\end{array}$ \\
3 & Severe & $<0.70$ & $\begin{array}{l}30 \% \leq \mathrm{FEV},<50 \% \\
\text { predicted } \\
\end{array}$ \\
& Very severe & $<0.70$ & $\begin{array}{l}\mathrm{FEV},<30 \% \\
\text { predicted }\end{array}$ \\
\hline
\end{tabular}

Abbreviations: $\mathrm{FEV}_{1}$, forced expiratory volume in one second; $\mathrm{FVC}$, forced vital capacity; GOLD, Global Initiative for Chronic Obstructive Lung Disease.

questionnaire can be used in both primary and secondary care settings. ${ }^{28}$ Patient age and gender do not influence CAT scores ${ }^{28}$ however, other factors that can affect CAT scores include severity of airflow obstruction, severity of dyspnea, and St George's Respiratory Questionnaire (SGRQ) total scores. ${ }^{26,28,30}$

\section{Comparison of health status assessment questionnaires}

Given the importance of HRQL in the management of COPD patients, many standard questionnaires have been developed to evaluate it. ${ }^{17}$ Validity and reliability are essential for a standard HRQL questionnaire, ${ }^{17}$ and the following sections provide a brief overview of some important disease-specific questionnaires used in COPD.

\section{St George's Respiratory Questionnaire}

The SGRQ is often used to evaluate HRQL in COPD patients. ${ }^{31}$ It is designed to measure the current patient's health status and to monitor changes after therapeutic intervention. ${ }^{31,32}$ The SGRQ consists of 76 items, divided into three sections including: symptoms (evaluating frequency and severity of several respiratory symptoms), activity (evaluating limitation of activities due to dyspnea and also activities that cause dyspnea), and impact (evaluating social and psychological disturbances secondary to pulmonary disease). ${ }^{20,31}$ Each item has a determined weight, and total scores range between 0 (the best state) and 100 (the worst state). ${ }^{20,31}$

\section{Clinical COPD Questionnaire}

The Clinical COPD Questionnaire consists of ten items that are divided in three parts comprising: symptoms (four items), functional state (four items), and mental state (two items). ${ }^{33}$ Scores can range from 0 (best state) to 6 (worst state).

\section{Chronic Respiratory Disease Questionnaire}

The Chronic Respiratory Disease Questionnaire was the first to introduce an evaluation of HRQL in COPD patients..$^{34,35}$ It contains 20 questions divided in four parts: dyspnea (five questions), emotional function (seven questions), fatigue (four questions), and mastery (four questions). ${ }^{34,35}$ The score ranges from 1 (maximum impairment) to 7 (no impairment). ${ }^{34,35}$

\section{Short-Form 36-item Health Survey}

The Short-Form 36-item Health Survey is a valid instrument for descriptive measurement of HRQL in COPD patients. ${ }^{33,36,37}$ It contains eight parts: physical function (ten items), role physical (four items), bodily pain (two items), general health (five items), vitality (four items), social function (two items), role emotional (three items), and mental health (five items). ${ }^{33}$ Scores can range between 0 (worst state) to 100 (best state).

\section{COPD Assessment Test}

A recent comprehensive systematic review by Weldam et al could not determine the best instrument for evaluating HRQL in COPD patients. ${ }^{17}$ Disease-specific questionnaires (SGRQ, CAT, Chronic Respiratory Disease Questionnaire) are superior to generic instruments for evaluating HRQL in COPD patients. ${ }^{17}$ However, given that the SGRQ consists of several items with different weights, the general application in routine clinical visits is difficult. ${ }^{38}$ The CAT and Clinical COPD Questionnaire have been developed to avoid the problems of the SGRQ. ${ }^{38}$

As mentioned, the CAT is a reliable and valid tool for obtaining important information regarding the impact of COPD on a patient's day-to-day life despite the small number of questions. ${ }^{30}$ Although there are other HRQL questionnaires that are also valid and reliable, some are too time-consuming and complicated for use at routine clinical visits. ${ }^{1,18,30}$ Previous studies have shown that the CAT has a strong correlation with the SGRQ. ${ }^{18,26}$ In contrast with other HRQL questionnaires, the CAT is a one-dimensional instrument and its total scores are easily calculated. ${ }^{39}$ The limited number of items makes the CAT questionnaire a simple and practical tool for routine clinical use. The main advantages of CAT are its simplicity and the fact that it can be completed rapidly by patients. ${ }^{38}$ Although the CAT contains only eight questions, the test overall covers the multidimensional aspects of COPD burden. ${ }^{23}$ By considering a range of severity in terms of important respiratory symptoms and physical activity, an acceptable evaluation of disease severity can be made. ${ }^{1}$ This is the main advantage of the CAT over other HRQL questionnaires. 
The CAT is useful clinically for assessing functional health status and the response to treatment.

\section{Spirometric assessment}

Spirometry is a simple physiological test that measures inhaled and exhaled volumes over a given period of time..$^{1,40}$ Spirometry has a pivotal role in the diagnosis of COPD, determination of its severity, and monitoring of disease progression. ${ }^{1,2,7,41,42}$ Spirometry is best performed with the patient in the sitting position. The patient should breathe in fully, and completely seal their lips around the mouthpiece. Next, they should force air out of their lungs until their chest feels empty of air, and then breathe in again and relax. The exhalation time should be 6 seconds but can continue for up to 15 seconds. ${ }^{1}$ The spirometric parameters used for diagnosis of COPD are $\mathrm{FEV}_{1}, \mathrm{FVC}$, and $\mathrm{FEV}_{1} / \mathrm{FVC}$. ${ }^{1,40}$

$\mathrm{FEV}_{1}$ is the maximal volume of air exhaled in the first second of a forced expiration, originating from a deep inspiration, and is expressed in liters or percent predicted of reference values. ${ }^{40} \mathrm{FVC}$ is the maximal volume of exhaled air with maximal forced effort after a deep inspiration, and is expressed in liters or percent predicted of reference values. ${ }^{40}$ $\mathrm{FEV}_{1} / \mathrm{FVC}$ is the expression of $\mathrm{FEV}_{1}$ as a proportion of $\mathrm{FVC}$, and is used for diagnosis of COPD. ${ }^{1}$ The $\mathrm{FEV}_{1} / \mathrm{FVC}$ ratio is between 0.70 and 0.80 in normal adults. A post-bronchodilator $\mathrm{FEV}_{1} / \mathrm{FVC}<0.70$ in the clinical setting confirms a diagnosis of COPD. ${ }^{1} \mathrm{FEV}_{1}$ declines over time, and more rapidly in COPD patients than in healthy people. ${ }^{1}$

\section{GOLD classification}

$\mathrm{FEV}_{1}$ is traditionally used as a marker of COPD severity. ${ }^{1,5,43,44}$ According to the GOLD guidelines, the severity of airflow limitation should be determined according to post-bronchodilator $\mathrm{FEV}_{1} \cdot{ }^{1}$

The classification of airflow limitation is shown in Table 2 .

\section{Assessment of exacerbations}

COPD is often associated with exacerbations involving decreased lung function. ${ }^{28,45}$ A COPD exacerbation is defined as an event in the natural course of the disease characterized by worsening of the patient's dyspnea, cough, and/or sputum production beyond day-to-day variability and needing a change in management. ${ }^{1,2,46}$ Patients who have two or more exacerbations per year are considered to have frequent exacerbations. ${ }^{1}$ Risk factors for frequent exacerbations include a history of previously treated exacerbations and worsening airflow obstruction. ${ }^{1,47}$ Assessment of COPD exacerbation is necessary since such episodes can lead to increased deterioration in lung function, worsened HRQL, and increased risk of mortality. ${ }^{1,45}$

\section{Assessment of comorbidities}

As mentioned earlier, ${ }^{48,49}$ COPD is not confined to the lungs and is a systemic inflammatory condition. ${ }^{5}$ Fabri and Rabe suggested the term "chronic systemic inflammatory syndrome" to reflect the complexity of the condition. ${ }^{14,50}$

Systemic levels of numerous inflammatory markers, such as highly sensitive C-reactive protein, interleukins, tumor necrosis factor- $\alpha$, and fibrinogen, are elevated in COPD. ${ }^{51}$ The extrapulmonary components of COPD can adversely affect patient health status. ${ }^{5,52,53}$ Although the importance of comorbidities in COPD is clear, the clinical and pathophysiological links between airway disease and the presence of comorbidities are still unknown. ${ }^{54}$

There are theories regarding the presence of comorbidities in COPD: the spillover of inflammatory markers from the lungs to the systemic circulation and subsequent deterioration of the condition, the presence of common risk factors for both COPD and comorbidities, such as smoking, aging, and physical inactivity, and the clustering of comorbidities. ${ }^{14,54-56}$ The clustering theory considers patients in five distinct clusters: a cachectic cluster with lower diffusion capacity and more hyperinflation; a metabolic cluster with less severe pulmonary impairment but significant metabolic derangement and low-grade inflammation; a cardiovascular cluster with increased blood pressure and subclinical atherosclerosis; a less comorbid cluster; and a psychological cluster with increased symptoms of anxiety and depression. ${ }^{56}$ The major comorbidities are shown in Table $3 .^{51}$

Cardiovascular disease is probably the most frequent and serious comorbidity in COPD. ${ }^{1,16,57}$ It must be borne in mind

Table 3 Major comorbidities in chronic obstructive pulmonary disease

\begin{tabular}{l}
\hline Cardiovascular disease \\
Ischemic heart disease \\
Hypertension \\
Heart failure \\
Atrial fibrillation \\
Osteoporosis \\
Mood disorder (anxiety, depression) \\
Diabetes \\
Metabolic syndrome \\
Musculoskeletal dysfunction \\
Anemia \\
Lung cancer \\
Gastroesophageal reflux
\end{tabular}


that ischemic heart disease, heart failure, atrial fibrillation, and hypertension are considered part of the spectrum of cardiovascular disease. ${ }^{1}$ Among the cardiovascular disease entities, hypertension is the most frequent comorbidity, ${ }^{1,16}$ and atrial fibrillation is the most frequent arrhythmia. ${ }^{1,58}$ Ischemic heart disease is an important comorbidity in COPD and the most common cause of death in affected patients. ${ }^{59}$ Due to their increased likelihood of myocardial injury, ischemic heart disease must be considered during the evaluation of COPD patients. ${ }^{1,60}$ About $30 \%$ of patients with stable COPD have evidence of heart failure, and this may be a source of confusion due to the similar symptoms (eg, dyspnea). ${ }^{1,61}$

Osteoporosis is another major comorbidity in COPD and can worsen the prognosis. ${ }^{1,16,57}$ Accompanying characteristics include low body mass index, low fat-free mass, and emphysema. ${ }^{1,62-64}$

Mood disorders, including anxiety and depression, are common comorbidities in COPD. ${ }^{1,65-68}$ A lower FEV a higher SGRQ score, younger age, female sex, presence of persistent cough, and a history of cardiovascular disease are associated with an increased risk of mood disorder in COPD patients. ${ }^{1,65}$

These important comorbidities undoubtedly have a significant impact on the phenotypic presentation of the disease and markedly affect outcomes in COPD. ${ }^{16}$ They are associated with increased morbidity and mortality, a poor prognosis, and a considerable higher economic burden. ${ }^{54}$ The main causes of mortality in COPD patients are nonrespiratory, and include cardiovascular disease (in approximately $25 \%$ of cases), lung cancer (in 20\%), and other diseases (in 30\%). ${ }^{16}$ Due to the important role of comorbidity in the phenotypic presentation and severity of COPD, noninvasive assessment of ventricular function (eg, echocardiography) and determination of blood sugar and highly sensitive C-reactive protein levels should be performed in addition to lung function studies. ${ }^{16}$

Comorbidities can occur at each stage of COPD severity and can adversely affect the disease course. ${ }^{1,69}$ Comorbidities associated with COPD increase the likelihood of exacerbations and hospitalization. ${ }^{1,70}$ The sequelae of COPD (eg, reduced physical activity) can also adversely affect the course of the comorbidities, ${ }^{1}$ and it is recommended that appropriate evaluation of comorbidities and treatment be considered in parallel with COPD assessment. ${ }^{1}$ As part of the assessment of COPD comorbidities, priority must be given to common and treatable conditions. ${ }^{1}$ Assessment and evaluation of individual comorbidities in COPD patients should be the same as in any other patient. ${ }^{1}$

\section{Combined COPD assessment}

Due to the multifactorial nature of COPD, spirometry alone is not sufficient for evaluating the disease and determining the burden of COPD. ${ }^{7,71,72}$ Previous studies have shown that $\mathrm{FEV}_{1}$ does not correlate with important clinical parameters in COPD, such as exercise tolerance, dyspnea, and health status. ${ }^{7,71-74}$ In 2011, GOLD introduced a new COPD assessment classification that includes not only the severity of airflow obstruction, but also the level of dyspnea according to the mMRC scale, CAT total score, and the frequency of exacerbations (Table 4). ${ }^{1}$ According to the GOLD 2011 guidelines, patients are categorized in four categories according to high risk versus low risk and more versus less symptoms. As shown in Table 4, evaluation of symptoms is based on the mMRC and CAT (less symptoms, mMRC $0-1$ or CAT $<10$; more symptoms, $\mathrm{mMRC} \geq 2$ or $\mathrm{CAT} \geq 10$ ). Evaluation of the patient's risk is also based on severity of airflow obstruction (low risk, GOLD 1 or 2; high risk, GOLD 3 or 4) and the annual frequency of exacerbations (low risk, $\leq 1$ per year; high risk, $\geq 2$ per year). ${ }^{1}$ The GOLD 2011 classification accompanied by assessment of potential comorbidities is a comprehensive method for evaluating COPD as compared with the findings of spirometry alone. ${ }^{1}$

\section{Improvement in patient-physician communication}

Patient-physician communication has an important role in the quality of care and treatment plans, and is a vital element of the care process. Successful patient-physician communication is required for effective management of COPD. ${ }^{75}$ There are studies showing that many patients and physicians are not satisfied regarding communication about COPD..$^{8,9,76}$ The dissatisfaction for patients may reflect an unmet need for information about the nature and course of COPD, the results of pulmonary function tests, and the therapeutic plan. ${ }^{75,77}$ One of the main problems for physicians in the interview is inadequate expression of symptoms by patients. ${ }^{9,76}$

Table 4 GOLD 20 I I classification (symptom/risk evaluation of COPD)

\begin{tabular}{lllll}
\hline Category & $\begin{array}{l}\text { GOLD } \\
\text { classification }\end{array}$ & $\begin{array}{l}\text { Exacerbations } \\
\text { per year }\end{array}$ & $\begin{array}{l}\text { CAT } \\
\text { scores }\end{array}$ & $\begin{array}{l}\text { mMRC } \\
\text { stage }\end{array}$ \\
\hline A & $\mathrm{I}-2$ & $\leq 1$ & $<10$ & $0-1$ \\
B & $\mathrm{I}-2$ & $\leq 1$ & $\geq 10$ & $\geq 2$ \\
C & $3-4$ & $\geq 2$ & $<10$ & $0-1$ \\
D & $3-4$ & $\geq 2$ & $\geq 10$ & $\geq 2$ \\
\hline
\end{tabular}

Abbreviations: COPD, chronic obstructive pulmonary disease; CAT, COPD Assessment Test; GOLD, Global Initiative for Chronic Obstructive Lung Disease; mMRC, modified Medical Research Council. 
Previous studies have shown that psychological factors are related to HRQL and positive perceptions about COPD can improve HRQL in COPD. ${ }^{22}$ More positive beliefs about the outcome of COPD and about the effectiveness of medical treatment can improve HRQL. ${ }^{22}$ Since the combination of illness perception, depression, and dyspnea can strongly affect HRQL, particular attention to these issues is important and standard questionnaires should be used to explore these issues during a consultation. ${ }^{22}$

Both parties have a responsibility to provide information if patient-physician communication is to be improved. . $^{75,78}$ Accommodating the patient's need for more information about COPD and for active participation in the decisionmaking process is helpful for increasing the patient's satisfaction level. ${ }^{75}$ Patient-centered interviewing techniques can also improve the satisfaction level of both parties. ${ }^{75,79-82}$ Disease-specific questionnaires like the CAT and Clinical COPD Questionnaire can improve patient-physician communication. ${ }^{14}$

Nelson and Hamilton ${ }^{75}$ recommend the following techniques to improve communication with COPD patients:

- notify the patients about diagnosis and test results

- improve disease education

- reduce risk factors, especially smoking

- demonstrate inhaler use and administration of medications.

\section{Effect of CAT on management decisions made by the physician}

Standard tools that can evaluate all aspects of the disease should be used for improving the quality of patient-physician communication. ${ }^{9}$ Improvement of patient-physician communication is one of the aims of CAT. ${ }^{9}$ The global guideline committees strongly recommend to consider the patient's perception about the disease burden on their HRQL. ${ }^{83}$ Applied correctly in clinical practice, such questionnaires could significantly improve the quality of management. ${ }^{83}$ By asking patients to complete short questionnaires like the CAT at home, health care workers can improve their quality of communication in addition to saving time. ${ }^{83}$

CAT scores can influence clinical decision-making and guide patient management. One expert committee ${ }^{84}$ makes the following recommendations based on CAT scores.

\section{CAT score $<10$}

The impact level of COPD will be low. Possible management considerations should include smoking cessation, annual influenza vaccination, reduction of risk factors, and therapeutic plans based on further clinical assessment.

\section{CAT score 10-20}

The impact level of COPD will be medium. In addition to the recommendations for patients with low-impact disease, the considerations include reviewing maintenance therapy, referral for pulmonary rehabilitation, reducing and managing exacerbations, and reviewing again for possible presence of risk factors.

\section{CAT score $21-30$}

The impact level will be high. In addition to the recommendations for patients with low-impact and medium-impact disease, the following items are recommended: referral to a pulmonologist (if the patient is managed in a primary care service) and consideration of additional pharmacological treatments.

\section{CAT score $>30$}

The impact level will be very high. The recommendations are the same as for patients with high-impact disease.

\section{Conclusion}

The CAT is a simple and valid instrument that can be used easily to improve patient-physician communication during routine clinical visits. Comprehensive assessment of COPD can be performed by gathering clinical data, spirometry, and the CAT score. Additionally, the CAT can help clinicians in clinical decision-making and appropriate management.

\section{Disclosure}

The authors report no conflicts of interest in this work.

\section{References}

1. Global Initiative for Chronic Obstructive Lung Disease. 2011 (updated December 2011). Available from: http://www.goldcopd.com. Accessed May 2, 2012.

2. Celli BR, MacNee W. Standards for the diagnosis and treatment of patients with COPD: a summary of the ATS/ERS position paper. Eur Respir J. 2004;23:932-946.

3. Akinbami LJ, Liu X. Chronic obstructive pulmonary disease among adults aged 18 and over in the United States, 1998-2009. NCHS Data Brief. 2011;63:1-8.

4. World Health Organization. World Health Report. Geneva, Switzerland: World Health Organization; 2000. Available from: http://www.who.int/ whr/2000/en/whr00_en.pdf. Accessed August 31, 2014.

5. Rolink M, van Dijk W, van den Haak-Rongen S, Pieters W, Schermer T, van den Bemt L. Using the DOSE index to predict changes in health status of patients with COPD: a prospective cohort study. Prim Care Respir J. 2013;22:169-174.

6. World Health Organization. COPD factsheet. Geneva, Switzerland: World Health Organization; 2008. Available from: http://www.who.int/ respiratory/copd/en/index.html. Accessed May 2, 2012.

7. Jones PW, Brusselle G, Dal Negro RW, et al. Patient-centered assessment of COPD in primary care: experience from a cross-sectional study of health-related quality of life in Europe. Prim Care Respir J. 2012;21: 329-336. 
8. Jones P, Harding G, Wiklund I, Berry P, Leidy N. Improving the process and outcome of care in COPD: development of a standardized assessment tool. Prim Care Respir J. 2009;18:208-215.

9. Gruffydd-Jones K, Marsden HC, Holmes S, et al. Utility of COPD Assessment Test (CAT) in primary care consultations: a randomized controlled trial. Prim Care Respir J. 2013;22:37-43.

10. Coulter A, Ellins J. Patient-focused interventions: a review of the evidence. Picker Institute Europe Health Foundation; 2006. Available from: http://www.health.org.uk/publications/patientfocused-interventions/. Accessed August 31, 2014.

11. Detmar SB, Muller MJ, Schornagel JH, Wever LD, Aaronson NK. Health-related quality-of-life assessments and patient-physician communication: a randomized controlled trial. JAMA. 2002;288: 3027-3034.

12. Freeman G, Horder JP, Howie JGR, et al. Evolving general practice consultation in Britain: issues of length and context. BMJ. 2002;324: 880-882.

13. Bourbeau J, Bartlett SJ. Patient adherence in COPD. Thorax. 2008;63: 831-838.

14. Miravitlles M, Ferrer J, Baró E, Lleonart M, Galera J. Differences between physician and patient in the perception of symptoms and their severity in COPD. Respir Med. 2013;107:1977-1985.

15. de Ridder DT, Theunissen NC, van Dulmen SM. Does training general practitioners to elicit patient's illness representations and action plans influence their communication as a whole? Patient Educ Couns. 2007;66:327-336.

16. Fabbri LM, Luppi F, Beghé B, Rabe KF. Complex chronic comorbidities of COPD. Eur Respir J. 2008;31:204-212.

17. Weldam SW, Schuurmans MJ, Liu R, Lammers JW. Evaluation of quality of life instruments for use in COPD care and research: a systematic review. Int J Nurs Stud. 2013;50:688-707.

18. Lari SM, Ghobadi H, Attaran D, Mahmoodpour A, Shadkam O, Rostami M. COPD assessment test (CAT): simple tool for evaluating quality of life of chemical warfare patients with chronic obstructive pulmonary disease. Clin Respir J. 2014;8:116-123.

19. Mahler DA. How should health-related quality of life be assessed in patients with COPD? Chest. 2000;117 Suppl 2:54S-58S.

20. Attaran D, Khajedaloui M, Jafarzadeh R, Mazloomi M. Health related quality of life in patients with chemical warfare induced COPD. Arch Iran Med. 2006;9:359-363.

21. Garrett S, Jenkinson T, Kennedy LG, Whitelock H, Gaisford P, Calin A. A new approach to defining disease status in ankylosing spondylitis: the Bath Ankylosing Spondylitis Disease Activity Index. J Rheumatol. 1994;21:2286-2291.

22. Weldam SW, Lammers JW, Decates RL, Schuurmans MJ. Daily activities and health-related quality of life in patients with chronic obstructive pulmonary disease - psychological determinants: a cross-sectional study. Health Qual Life Outcomes. 2013;11:190.

23. Ghobadi H, Sadeghieh S, Kameli A, Lari SM. The relationship between COPD assessment test (CAT) scores and severity of airflow obstruction in stable COPD patients. Tanaffos. 2012;11:22-26.

24. Xu W, Collet JP, Shapiro S, et al. Negative impacts of unreported COPD exacerbations on health-related quality of life at 1 year. Eur Respir J. 2010;35:1022-1030.

25. Jones PW, Harding G, Wiklund I, et al. Tests of the responsiveness of the COPD assessment test following acute exacerbation and pulmonary rehabilitation. Chest. 2012;142:134-140.

26. Jones PW, Brusselle G, Dal Negro RW, et al. Properties of the COPD assessment test in a cross-sectional European study. Eur Respir J. 2011;38:29-35.

27. Kelly JL, Bamsey O, Smith C, et al. Health status assessment in routine clinical practice: the chronic obstructive pulmonary disease assessment test score in outpatients. Respiration. 2012;84:193-199.

28. Mackay AJ, Donaldson GC, Patel AR, Jones PW, Hurst JR, Wedzicha JA. Usefulness of the Chronic Obstructive Pulmonary Disease Assessment Test to evaluate severity of COPD exacerbations. Am J Respir Crit Care Med. 2012;185:1218-1224.
29. Kon SS, Canavan JL, Jones SE, et al. Minimum clinically important difference for the COPD Assessment Test: a prospective analysis. Lancet Respir Med. 2014;2:195-203.

30. Jones PW, Harding G, Berry P, Wiklund I, Chen WH, Kline Leidy N. Development and first validation of the COPD Assessment Test. Eur Respir J. 2009;34:648-654.

31. Daudey L, Peters JB, Molema J, et al. Health status in COPD cannot be measured by the St George's Respiratory Questionnaire alone: an evaluation of the underlying concepts of this questionnaire. Respir Res. 2010;11:98.

32. Jones PW, Quirk FH, Baveystock CM. The St-George Respiratory Questionnaire. Respir Med. 1991;85:25-31.

33. Ställberg B, Nokela M, Ehrs PO, Hjemdal P, Jonsson EW. Validation of the clinical COPD Questionnaire (CCQ) in primary care. Health Qual Life Outcomes. 2009;7:26.

34. Molken MR, Roos B, Van Noord JA. An empirical comparison of the St George's Respiratory Questionnaire (SGRQ) and the Chronic Respiratory Disease Questionnaire (CRQ) in a clinical trial setting. Thorax. 1999;54:995-1003.

35. Guyatt GH, Berman LB, Townsend M, et al. A measure of quality of life for clinical trials in chronic lung disease. Thorax. 1987;42:773-778.

36. Alonso J, Prieto L, Ferrer M, et al. Testing the measurement properties of the Spanish version of the SF-36 Health Survey among male patients with chronic obstructive pulmonary disease. Quality of Life in COPD Study Group. J Clin Epidemiol. 1998;51:1087-1094.

37. Mahler DA, Mackowiak JI. Evaluation of the Short-Form 36-item questionnaire to measure health-related quality of life in patients with COPD. Chest. 1995; 107:1585-1589.

38. Ringbaek T, Martinez G, Lange P. A comparison of the assessment of quality of life with CAT, CCQ, and SGRQ in COPD patients participating in pulmonary rehabilitation. COPD. 2012;9:12-15.

39. Tsiligianni IG, van der Molen T, Moraitaki D, et al. Assessing health status in COPD. A head-to-head comparison between the COPD assessment test (CAT) and the clinical COPD questionnaire (CCQ). BMC Pulm Med. 2012;12:20.

40. American Thoracic Society. Standards for the diagnosis and care of patients with chronic obstructive pulmonary disease. Am J Respir Crit Care Med. 1995;52:S77-S121.

41. National Collaborating Centre for Chronic Conditions. Chronic obstructive pulmonary disease: national clinical guideline on management of chronic obstructive pulmonary disease in adults in primary and secondary care. Thorax. 2004;59 Suppl 1:172-181.

42. Bettoncelli G, Blasi F, Brusasco V, et al. The clinical and integrated management of COPD. An official document of AIMAR (Interdisciplinary Association for Research in Lung Disease), AIPO (Italian Association of Hospital Pulmonologists), SIMER (Italian Society of Respiratory Medicine), SIMG (Italian Society of General Medicine). Multidiscip Respir Med. 2014;9:25.

43. Celli BR, Cote CG, Marin JM, et al. The body-mass index, airflow obstruction, dyspnea, and exercise capacity index in chronic obstructive pulmonary disease. $N$ Engl J Med. 2004;350:1005-1012.

44. Celli BR, Cote CG, Lareau SC, Meek PM. Predictors of survival in COPD: more than just the $\mathrm{FEV}_{1}$. Respir Med. 2008;102:S27-S35.

45. Tu YH, Zhang Y, Fei GH. Utility of the CAT in the therapy assessment of COPD exacerbations in China. BMC Pulm Med. 2014;14:42.

46. Woods JA, Wheeler JS, Finch CK, Pinner NA. Corticosteroids in the treatment of acute exacerbations of chronic obstructive pulmonary disease. Int J Chron Obstruct Pulmon Dis. 2014;9:421-430.

47. Hurst JR, Vestbo J,Anzueto A, et al. Susceptibility to exacerbation in chronic obstructive pulmonary disease. $N$ Engl J Med. 2010;363:1128-1138.

48. Attaran D, Lari SM, Khajehdaluee M, et al. Highly sensitive C-reactive protein levels in Iranian patients with pulmonary complication of sulfur mustard poisoning and its correlation with severity of airway diseases. Hum Exp Toxicol. 2009;28:739-745.

49. Attaran D, Lari SM, Towhidi M, et al. Interleukin-6 and airflow limitation in chemical warfare patients with chronic obstructive pulmonary disease. Int J Chron Obstruct Pulmon Dis. 2010;5:335-340. 
50. Fabbri LM, Rabe KF. From COPD to chronic systemic inflammatory syndrome? Lancet. 2007;370:797-799.

51. Sinden NJ, Stockley RA. Chronic obstructive pulmonary disease: an update of treatment related to frequently associated comorbidities. Ther Adv Chronic Dis. 2010;1:43-57.

52. Sin DD, Anthonisen NR, Soriano JB, Agusti AG. Mortality in COPD: role of comorbidities. Eur Respir J. 2006;28:1245-1257.

53. Tsiligianni I, Kocks J, Tzanakis N, Siafakas N, van der Molen T. Factors that influence disease-specific quality of life or health status in patients with COPD: a review and meta-analysis of Pearson correlations. Prim Care Respir J. 2011;20:257-268.

54. Clini EM, Boschetto P, Lainscak M, Janssens W. Comorbidities in chronic obstructive pulmonary disease from assessment to treatment. Biomed Res Int. 2014;2014:414928.

55. Barnes PJ, Celli BR. Systemic manifestations and comorbidities of COPD. Eur Respir J. 2009;33:1165-1185.

56. Vanfleteren LE, Spruit MA, Groenen M, et al. Clusters of comorbidities based on validated objective measurements and systemic inflammation in patients with chronic obstructive pulmonary disease. Am J Respir Crit Care Med. 2013;187:728-735.

57. Soriano JB, Visick GT, Muellerova H, Payvandi N, Hansell AL. Patterns of comorbidities in newly diagnosed $\mathrm{COPD}$ and asthma in primary care. Chest. 2005;128:2099-2107.

58. Buch P, Friberg J, Scharling H, Lange P, Prescott E. Reduced lung function and risk of atrial fibrillation in the Copenhagen City Heart Study. Eur Respir J. 2003;21:1012-1016.

59. Mannino DM, Buist AS, Petty TL, et al. Lung function and mortality in the United States: data from the First National Health and Nutrition Examination Survey follow up study. Thorax. 2003;58:388-393.

60. Brekke PH, Omland T, Smith P, Soyseth V. Underdiagnosis of myocardial infarction in COPD-Cardiac Infarction Injury Score (CIIS) in patients hospitalized for COPD exacerbation. Respir Med. 2008; 102:1243-1247.

61. Rutten FH, Cramer MJ, Grobbee DE, et al. Unrecognized heart failure in elderly patients with stable chronic obstructive pulmonary disease. Eur Heart J. 2005;26:1887-1894.

62. McAllister DA, MacLay JD, Mills NL, et al. Arterial stiffness is independently associated with emphysema severity in patients with chronic obstructive pulmonary disease. Am J Respir Crit Care Med. 2007;176:1208-1214.

63. Bolton CE, Cannings-John R, Edwards PH, et al. What community measurements can be used to predict bone disease in patients with COPD? Respir Med. 2008;102:651-657.

64. Bolton CE, Ionescu AA, Shiels KM, et al. Associated loss of fat-free mass and bone mineral density in chronic obstructive pulmonary disease. Am J Respir Crit Care Med. 2004;170:1286-1293.

65. Hanania NA, Mullerova H, Locantore NW, et al. Determinants of depression in the ECLIPSE chronic obstructive pulmonary disease cohort. Am J Respir Crit Care Med. 2011;183:604-611.

66. Kunik ME, Roundy K, Veazey C, et al. Surprisingly high prevalence of anxiety and depression in chronic breathing disorders. Chest. 2005;127:1205-1211.

67. Ng TP, Niti M, Tan WC, Cao Z, Ong KC, Eng P. Depressive symptoms and chronic obstructive pulmonary disease: effect on mortality, hospital readmission, symptom burden, functional status, and quality of life. Arch Intern Med. 2007;167:60-67.

Patient Related Outcome Measures

\section{Publish your work in this journal}

Patient Related Outcome Measures is an international, peer-reviewed, open access journal focusing on treatment outcomes specifically relevant to patients. All aspects of patient care are addressed within the journal and practitioners from all disciplines are invited to submit their work as well as healthcare researchers and patient support groups.
68. Maurer J, Rebbapragada V, Borson S, et al. Anxiety and depression in COPD: current understanding, unanswered questions, and research needs. Chest. 2008;134(Suppl 4):43S-56S.

69. Decramer M, Celli B, Kesten S, Lystig T, Mehra S, Tashkin DP; UPLIFT Investigators. Effect of tiotropium on outcomes in patients with moderate chronic obstructive pulmonary disease (UPLIFT): a prespecified subgroup analysis of a randomised controlled trial. Lancet. 2009;374:1171-1178.

70. Mannino DM, Thorn D, Swensen A, Holguin F. Prevalence and outcomes of diabetes, hypertension and cardiovascular disease in COPD. Eur Respir J. 2008;32:962-969.

71. Cazzola M, MacNee W, Martinez FJ, et al; on behalf of the American Thoracic Society/European Respiratory Society Task Force on outcomes of COPD. Outcomes of COPD pharmacological trials: from lung function to biomarkers. Eur Respir J. 2008;31:416-469.

72. Gruffydd-Jones K. A national strategy for the management of chronic obstructive pulmonary disease (COPD) in England: aiming to improve the quality of care for patients. Prim Care Respir J. 2008;17 Suppl 1: S1-S8.

73. Hay JG, Stone P, Carter J, et al. Bronchodilator reversibility exercise performance and breathlessness in stable chronic obstructive pulmonary disease. Eur Respir J. 1992;5:659-664.

74. O'Donnell DE, Lam M, Webb KA. Spirometric correlates of improvement in exercise performance after anticholinergic therapy in chronic obstructive pulmonary disease. Am J Respir Crit Care Med. 1999;160:542-549.

75. Nelson M, Hamilton HE. Improving in-office discussion of chronic obstructive pulmonary disease: results and recommendations from an in-office linguistic study in chronic obstructive pulmonary disease. Am J Med. 2007;120(8 Suppl 1):S28-S32.

76. Barry CA, Bradley CP, Britten N, Stevenson FA, Barber N. Patients' unvoiced agendas in general practice consultations: qualitative study. BMJ. 2000;320:1246-1250.

77. Koning CJ, Maille AR, Stevens I, Dekker FW. Patients' opinions on respiratory care: do doctors fulfill their needs? J Asthma. 1995;32: 355-363.

78. Oliver SM. Living with failing lungs: the doctor-patient relationship. Fam Pract. 2001;18:430-439.

79. Frymoyer JW, Frymoyer NP. Physician-patient communication: a lost art? J Am Acad Orthop Surg. 2002;10:95-105.

80. Ishikawa H, Takayama T, Yamazaki Y, et al. Physician-patient communication and patient satisfaction in Japanese cancer consultations. Soc Sci Med. 2002;55:301-311.

81. Martin LR, Jahng KH, Golin CE, DiMatteo MR. Physician facilitation of patient involvement in care: correspondence between patient and observer reports. Behav Med. 2003;28:159-164.

82. Roter DL, Larson S, Shinitzky H, et al. Use of an innovative video feedback technique to enhance communication skills training. Med Educ. 2004;38:145-157.

83. van der Molen T, Diamant Z, Kocks JW, Tsiligianni IG. The use of health status questionnaires in the management of chronic obstructive pulmonary disease patients in clinical practice. Expert Rev Respir Med. 2014;8:479-491.

84. Jones PW, Jenkins C, Bauerle O; on behalf of the CAT Development Steering Group. The COPD Assessment Test healthcare professional user guide: expert guidance on frequently asked questions. Available from: http://www.catestonline.org/images/UserGuides/CATHCPUser\%20 guideEn.pdf. Accessed August 31, 2014.

The manuscript management system is completely online and includes a very quick and fair peer-review system. Visit http://www.dovepress. com/testimonials.php to read real quotes from published authors. 